\title{
Phenotypic characterization of a Candida albicans strain deficient in its major exoglucanase
}

\author{
María del Mar González, ${ }^{1}$ Rosalía Drez-Orejas, ${ }^{1}$ Gloria Molero, ${ }^{1}$ Alberto \\ M. Álvarez, ${ }^{2}$ Jesús Pla, ${ }^{1}$ César Nombela ${ }^{1}$ and Miguel Sánchez-Pérez ${ }^{2}$
}

\begin{abstract}
Author for correspondence: Miguel Sánchez-Pérez. Tel: +34 1 3941746. Fax: + 3413941745. e-mail: miguelsp@eucmax.sim.ucm.es
\end{abstract}

Department of Microbiology $\mathrm{II}^{1}$ and Flow and Confocal Cytometry Unit (CCF)' Faculty of Pharmacy, University Complutense of Madrid, 28040 Madrid, Spain

\begin{abstract}
Both alleles of the XOG1 gene of Candida albicans, which encodes a protein with exoglucanase activity, were sequentially disrupted. Enzymic analysis of either cell extracts or culture supernatants of disrupted strains revealed that this gene is responsible for the major exoglucanase activity in C. albicans, although residual exoglucanase activity could still be detected. xog1 null mutants showed similar growth rates in both rich and minimal liquid medium as compared to the wild-type strain, indicating that the enzyme is not essential for C. albicans growth. In addition, no differences were observed between wild-type and xog1 null mutants with respect to their ability to undergo dimorphic transition. However, small but repeatable differences were found between the wild-type and the null mutant with respect to susceptibility to chitin and glucan synthesis inhibitors. Using a murine model of experimental infection, no significant differences in virulence were observed. The xog1 null strain is thus a suitable recipient for studying Candida gene expression using the exoglucanase as a reporter gene.
\end{abstract}

Keywords: Candida albicans, exoglucanase, gene disruption, reporter gene, pathogenesis

\section{INTRODUCTION}

The fungal cell wall is an essential structure involved in many crucial aspects of fungal cell physiology. $\beta$-Glucan, a cell-wall polymer of $\beta$-glucose linked by $1,3-\beta$-bonds with occasional $1,6-\beta$-branching, is one of its major components, contributing significantly to cell wall mechanical strength and being partially responsible for the generation of a network in which other cell-wall components are assembled. In Saccharomyces cerevisiae, a set of different $1,3-\beta$-glucanases involved in $\beta$-glucan degradation have been characterized. Glucanases play an important role in cell wall construction (Cid et al., 1994; Nombela et al., 1988) although individual members within this group are redundant. The EXG1 gene, which was cloned by complementation of a mutant strain deficient in glucanase activity (Nebreda et al., 1986, 1987; Santos et al., 1979b) using a strategy involving the overproduction of glycosidases (Kuranda

Abbreviations: FDGP, fluorescein di-( $\beta$-D-glucopyranoside); 5-FOA, 5 fluoroorotic acid; MUG, 4-methylumbelliferyl $\beta$-D-glucoside; PNPG, $p$ nitrophenyl $\beta$-D-glucopyranoside.
\& Robbins, 1987), codes for a $51 \mathrm{kDa}$ polypeptide (Vázquez de Aldana et al., 1991) responsible for most of the glucanase activity in $S$. cerevisiae, although with no evident role (Santos et al., 1979a, 1982) in morphogenesis. The EXG2 gene (Cid et al., 1995) displays significant homology with EXG1 but has an additional C-terminal region that is apparently responsible for its correct location and assembly in the cell wall (Correa, 1993; del Rey et al., 1994). The third exoglucanase gene (or activity), SSG1, encodes a sporulation-specific exoglucanase (Muthukumar et al., 1993; San Segundo et al., 1993). Our understanding of the role of glucanases in $S$. cerevisiae is far from complete and there is an evident lack of knowledge about their role in pathogenic fungi.

Candida albicans is an opportunistic pathogenic yeast responsible for a steadily increasing incidence of fungal diseases among industrialized countries (Fox, 1993). Genetic manipulation of this yeast has been difficult since it is diploid and lacks a sexual cycle (Kurtz et al., 1990). However, in recent years, some of the tools necessary for gene isolation (Cannon et al., 1990, 1992; Herreros et al., 1992; Pla et al., 1995) have been developed. Biochemical work in C. albicans has identi- 
fied a major glucanase activity located in the periplasm of the cell (Molina et al., 1987); this was later shown to be due to a non-glycosylated $40 \mathrm{kDa}$ protein (Luna Arias et al., 1991). Recently, the XOG1 gene from C. albicans has been cloned and shown to encode a 438 amino acid exo-1,3- $\beta$-glucanase which has both sequence $(58 \%$ identity) and antigenic homologies with $S$. cerevisiae Exg1p (Chambers et al., 1993). This gene has been assigned to chromosome I (Dr P. Sullivan, http://www. alces.med.umn.edu/candida.html). However, the physiological relevance of the XOG1 gene has not been explored. In this work we constructed C. albicans $x \log 1$ mutant strains using the strategy recently developed by Fonzi \& Irwin (1993) to address its functional implications and its role in virulence.

\section{METHODS}

Media and culture conditions. Yeast and bacterial strains are listed in Table 1 . Yeast strains were routinely grown in YED medium $\left(20 \mathrm{~g}\right.$ glucose $\mathrm{l}^{-1}, 10 \mathrm{~g}$ yeast extract $\left.\mathrm{l}^{-1}\right)$ or minimal medium $\left(6.7 \mathrm{~g}\right.$ yeast nitrogen base without amino acids $\mathrm{l}^{-1}$, $20 \mathrm{~g}_{\text {glucose }} \mathrm{I}^{-1}$ ) supplemented with $40 \mathrm{mg}$ uridine $\mathrm{l}^{-1}$ when necessary. C. albicans $\mathrm{Ura}^{-}$revertants were selected at $30^{\circ} \mathrm{C}$ upon excision of the $C$. albicans $U R A 3$ gene from integrative transformants (see below) on the basis of the resistance of the $\mathrm{Ura}^{-}$revertants to 5-fluoroorotic acid (5-FOA, SCM Specialty Chemicals). The 5-FOA plates were prepared as described previously (Boeke et al., 1987) but $25 \mu \mathrm{g}$ uridine $\mathrm{ml}^{-1}$ was used instead of uracil. Measurements of yeast conversion to hyphae were performed in Lee's medium (Lee et al.,1975) at $37^{\circ} \mathrm{C}$. Cell growth was estimated by optical density at $600 \mathrm{~nm}$. Escherichia coli strains were grown at $37^{\circ} \mathrm{C}$ in Luria-Bertani (LB) broth or Terrific broth (TB) supplemented with $100 \mu \mathrm{g}$ ampicillin $\mathrm{ml}^{-1}$ for plasmid selection.

Molecular biology techniques. All DNA manipulations were carried out using standard protocols (Sambrook et al., 1989). Restriction enzymes were supplied by Boehringer Mannheim. PCR amplification reactions used a $100 \mu \mathrm{l}$ reaction volume containing $10 \mathrm{mM}$ Tris/ $\mathrm{HCl} \mathrm{pH} 8.3,1.5 \mathrm{mM} \mathrm{MgCl} 2,50 \mathrm{mM}$
$\mathrm{KCl}, 0 \cdot 1 \mathrm{~g}$ gelatin $\mathrm{l}^{-1}, 50 \mu \mathrm{M}$ dNTPs, $1.5 \mu \mathrm{M}$ of each oligonucleotide primer and approximately 1 ng plasmid DNA. The reaction was started by the addition of 1 unit Taq polymerase (Boehringer Mannheim). After an initial incubation step at $94^{\circ} \mathrm{C}$ for $3 \mathrm{~min}$, the samples were subjected to 30 cycles ( $2 \mathrm{~min}$ at $92{ }^{\circ} \mathrm{C}, 1.5 \mathrm{~min}$ at $58^{\circ} \mathrm{C}$, and $2 \mathrm{~min}$ at $72^{\circ} \mathrm{C}$ ) using the following oligonucleotide primers: Olihis, $5^{\prime}$-cgccagctcgattctggtactgc-3' (23 oligonucleotides), which hybridizes with the fragment included between positions 854 and 877 of the bis gene; Oliura, 5'-agatccagatattgaaggtaaaagg- $3^{\prime}$ (25 oligonucleotides), which hybridizes with the fragment included between positions 1211 and 1236 of the URA3 gene; and Olixog, 5'-AGCAGACCATTCACCAGCGACG-3' (22 oligonucleotides), which hybridizes with the fragment included between positions 1451 and 1473 of the XOG1 gene. The Ura ${ }^{+}$ transformants were analysed using the Oliura-Olixog primer pair; for $\mathrm{Ura}^{-}$analysis, the Olihis-Olixog primer pair was used.

C. albicans strain construction. The C. albicans strains used are listed in Table 1 . To obtain a C. albicans xog1 null strain, we used the standard strategy devised by Fonzi \& Irwin (1993). Plasmid pE1 was obtained by insertion of a $3.8 \mathrm{~kb}$ BamHI-BglII from the plasmid pCUB-6 (provided by Dr W. A. Fonzi, Georgetown University Medical Center, USA) containing the bisG-URA3-hisG cassette in the StyI site of plasmid BS-XOG1, which is a pBluescript derivative containing an EcoRI-SalI fragment from plasmid pXAG1 (provided by Dr P. A. Sullivan, University of British Columbia, Canada) subcloned in the EcoRI-SalI fragment of pBluescript KS (Stratagene). This $8.3 \mathrm{~kb}$ plasmid was then digested with BstXI and PstI and used to transform the CAI-4 strain, thus promoting homologous recombination at the XOG1 locus (the disruption strategy is shown in Fig. 1a). In this way, strains CNC30-a and $\mathrm{CNC} 30-\mathrm{b}$ were selected from among the positive $\mathrm{Ura}^{+}$ transformants and shown both by PCR (data not shown) and Southern blot (Fig. 1b) analysis to display the required integration event in both alleles [the alleles of this strain display restriction fragment polymorphism for the restriction enzyme BglII (Chambers et al., 1993)]. Strains CNC31-a and CNC31-b were isolated as spontaneous $\mathrm{Ura}^{-}$mitotic recombinants of strains $\mathrm{CNC} 30-\mathrm{a}$ and $\mathrm{CNC} 30-\mathrm{b}$, respectively.

Table 1. Strains used in this study

\begin{tabular}{|c|c|c|}
\hline Strain ${ }^{*}$ & Relevant genotype or phenotype & Source \\
\hline \multicolumn{3}{|l|}{ C. albicans } \\
\hline SC5314 & Wild-type & Gillum et al. (1984) \\
\hline CAI-4 & $\Delta u r a 3:: \lambda i m m 434 / \Delta u r a 3:: \lambda i m m 434$ & Fonzi et al. (1993) \\
\hline CNC30-a & 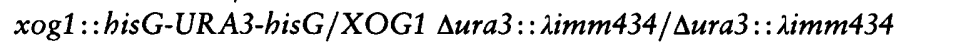 & This work \\
\hline CNC30-b & 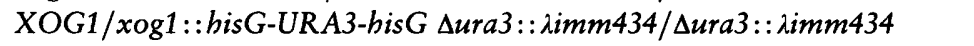 & This work \\
\hline CNC31-a & xog1::hisG/XOG1 $\Delta u r a 3:: \lambda i m m 434 / \Delta u r a 3:: \lambda i m m 434$ & This work \\
\hline CNC31-b & 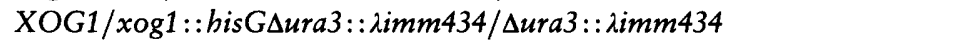 & This work \\
\hline CNC32-a & 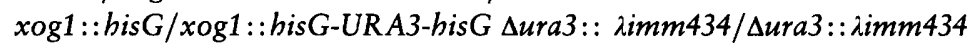 & This work \\
\hline $\mathrm{CNC} 32-\mathrm{b}$ & xog1::hisG-URA3-hisG/xog1::hisG $\Delta u r a 3:: \lambda i m m 434 / \Delta u r a 3:: \lambda i m m 434$ & This work \\
\hline CNC33-a & xog1:: hisG/xog1:: hisG $\Delta u r a 3:: \lambda i m m 434 / \Delta u r a 3:: \lambda i m m 434$ & This work \\
\hline CNC33-b & xog1::hisG/xog1::hisG $\Delta u r a 3:: \lambda i m m 434 / \Delta u r a 3:: \lambda i m m 434$ & This work \\
\hline \multicolumn{3}{|l|}{ E. coli } \\
\hline $\mathrm{DH} 5 \alpha \mathrm{F}^{\prime}$ & $\begin{array}{l}\mathrm{K}-12 \Delta(\text { lacZYA-argF)U169 supE44 thi-1 recA1endA1 hsdR17 gyrA } \\
\quad \text { relA1( }(80 \text { lacZ } \Delta M 15) \mathrm{F}^{\prime}\end{array}$ & Hanahan et al. (1988) \\
\hline
\end{tabular}

* The letter $\mathbf{a}$ or $\mathrm{b}$ in $\mathrm{C}$. albicans CNC strain designations refers to which chromosomal homologue has been affected in the gene replacement. 


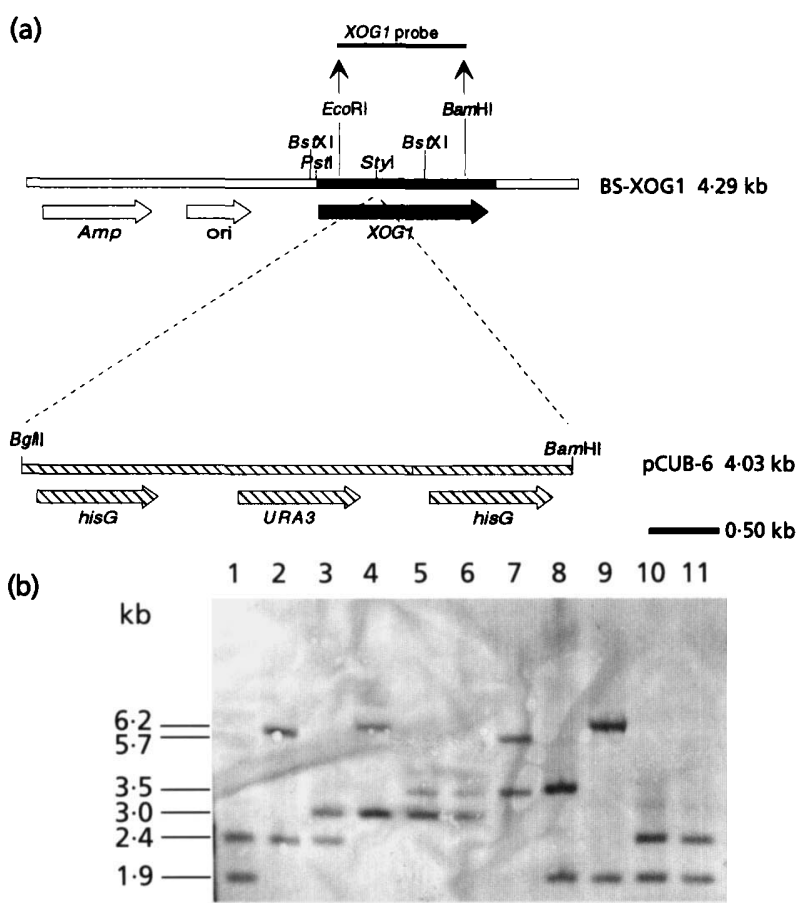

Fig. 1. Strategy used for disruption of both alleles of the XOG1 gene in C. albicans strain CAl-4. (a) The hisG-URA3-hisG construction was inserted at the Styl site in the XOG1 gene. BstXI-Pstl sites were used to force the integration at the XOG1 locus. Genomic DNA was digested with Bg/II and Pstl and analysed by Southern blotting using a probe which contained almost the entire XOG1 gene (EcoRI-BamHI). (b) Southern hybridization analysis of DNA from strains obtained during the disruption process. Lanes: 1, CAI-4 (wild-type, Ura-); 2, CNC30-a (xog1::hisG-URA3-hisGIXOG1); 3, CNC31-a (xog1::hisGIXOG1); 4, CNC32-a (xog1::hisG/xog1::hisG-URA3-hisG); 5, CNC33-a (xog1::hisG/xog1::hisG); 6, CNC33-b (xog1::hisG/xog1::hisG); 7. CNC32-b (xog1::hisG-URA3-hisG/xog1::hisG); 8, CNC31-b (XOG1/XOg1::hisG); 9, CNC30-b (XOG1/xog1::hisG-URA3-hisG); 10, CAl-4 (wild-type, Ura'); 11, 1001 (wild-type, Ura ${ }^{+}$). The 2.4 and $1.9 \mathrm{~kb}$ bands correspond to the wild-type xog1 gene, the 5.7 and $6.2 \mathrm{~kb}$ bands to the xog1::hisG-URA-hisG mutation, and the 3.0 and $3.5 \mathrm{~kb}$ bands to the $x \circ 91$ :: his mutation.

Repetition of this procedure allowed us to isolate strains CNC32-a and CNC32-b (Ura ${ }^{+}$background) and CNC33-a and CNC33-b (Ura ${ }^{-}$background) using both CNC31-a (CNC32-a and $C N C 33-a)$ and CNC31-b (CNC32-b and CNC33-b) as starting strains for transformation. Southern blot analysis was carried out using a $1 \cdot 1 \mathrm{~kb}$ Eco RI-Bam $\mathrm{HI}$ internal fragment as probe (Fig. 1a).

Flow cytometry. Preparation of cells for flow cytometry assays of exoglucanase activity was performed as described by Cid $e t$ al. (1994). Briefly, cells were incubated in minimal medium supplemented with $40 \mathrm{mg}$ uridine $\mathrm{l}^{-1}$ until the late-exponential phase. Two $0.1 \mathrm{ml}$ culture samples were transferred to two Eppendorf tubes. Cells were centrifuged and the supernatant was removed. The pellet was washed once with $0.05 \mathrm{M}$ acetate buffer $\mathrm{pH} 5.3$, resuspended in $0.05 \mathrm{ml}$ of the same buffer and $2.5 \mu \mathrm{l}$ of a $1 \mathrm{mg} \mathrm{ml}^{-1}$ dilution of fluorescein di- $(\beta-\mathrm{D}-\mathrm{gluco}-$ pyranoside) (FDGP, Sigma) was added. The remaining tube was left as a control without fluorogenic substrate. Both tubes were incubated at $30^{\circ} \mathrm{C}$ for $3 \mathrm{~h}$ in darkness. A $0.5 \mathrm{ml}$ aliquot of $50 \mathrm{mg} \mathrm{l}^{-1}$ propidium iodide in PBS $(0.145 \mathrm{M}$ sodium chloride, $0 \cdot 15 \mathrm{M}$ sodium phosphate) was added to each sample to discriminate dead cells (de la Fuente et al., 1992) and the samples $\left(1 \times 10^{4}\right.$ cells $)$ were immediately analysed on a FACScan flow cytometer (Becton-Dickinson). The fluorescence emitted by the fluorescein released was measured in fluorescence mean units (FL1) on a log scale ( $x$ axis) against the relative cell number ( $y$ axis). A rough estimation of the amount of chitin was accomplished by flow cytometry: approximately $1 \times 10^{4}$ cells were recovered from exponentially growing cultures, washed once with $0.5 \mathrm{ml}$ PBS and stained with calcofluor white at $10 \mu \mathrm{g} \mathrm{ml}^{-1}$ for $30 \mathrm{~min}$ at $30^{\circ} \mathrm{C}$ in darkness. The fluorescence emitted by calcofluor bound to chitin was measured on a BRYTE HS (Bio-Rad) flow cytometer equipped with a $\mathrm{Xe}-\mathrm{Hg}$ lamp. Flow cytometry analyses were performed twice using three different clones each time.

Confocal microscopy. Preparation of cells for primuline staining and confocal analysis was performed as follows. Cells from a culture in the late-exponential phase were washed with PBS and resuspended in $0.5 \mathrm{ml}$ PBS with $1 \mu \mathrm{l}$ of a $1 \mathrm{mg} \mathrm{ml}^{-1}$ dilution of primuline. The samples were observed after $30 \mathrm{~min}$ of incubation at room temperature in darkness and were analysed on a MRC1000 confocal microscope (Bio-Rad). The images obtained were selected from z-reconstruction on the plane where bud-scars were observed. Confocal analyses were performed twice using three different clones each time.

Glucanase activity assays. For the detection of $\beta$-glucanase activity in solid cultures, cells were grown on solid minimal medium supplemented with amino acids for 2-3 $\mathrm{d}$ and then covered with an overlay containing the substrate 4-methylumbelliferyl $\beta$-D-glucoside (MUG, Sigma). The overlay was prepared by mixing equal volumes of melted agar $\left(10 \mathrm{~g} \mathrm{l}^{-1}\right)$ and a solution of $0.3 \mathrm{~g} \mathrm{l}^{-1}$ MUG in $0.05 \mathrm{M}$ acetate buffer $\mathrm{pH} 5.3$, pouring the mixture over the plate surface and allowing it to solidify at room temperature. The plates were then further incubated at $30^{\circ} \mathrm{C}$ for $3 \mathrm{~h}$ and observed under UV light $(\lambda=260 \mathrm{~nm}$ ). Positive colonies (i.e. producing exoglucanase) show a white luminescence. This protocol is a slight modification of a previous one (Santos et al., 1979b).

Cell-free extracts were prepared from freshly harvested cells after disruption in a Braun homogenizer as previously described (Fleet \& Manners, 1976). Assays of 1,3- $\beta$-glucanase activity were based on the release of reducing sugars from laminarin, which were quantified using previously described methods (Ashwell, 1957; Somogyi, 1952). The reaction mixtures contained the enzyme preparation in a total of $250 \mu \mathrm{l}$ $0.001 \mathrm{M}$ sodium succinate buffer $\mathrm{pH} 5 \cdot 3$. The corresponding substrate was added to a final concentration of $2 \cdot 5 \mathrm{~g} \mathrm{l}^{-1}(\mathrm{w} / \mathrm{v})$. Incubations were performed at $37^{\circ} \mathrm{C}$ for $30 \mathrm{~min}$. One unit of enzyme activity (EU) was defined as the amount of enzyme which releases $1 \mathrm{nmol}$ of the measured reaction product per min under the reaction conditions. Protein concentrations were determined either by the method of Bradford (1976) (in both cases using BSA as standard) or spectrophotometrically at $\mathrm{OD}_{595}$ (Beckman spectrophotometer DU 640). Specific activity was defined as units of enzyme activity (mg protein $)^{-1}$.

Activity against $p$-nitrophenyl $\beta$-D-glucopyranoside (PNPG, Sigma) was measured spectrophotometrically $(\lambda=410 \mathrm{~nm})$ after incubation of $0.125 \mathrm{ml}$ of cell-free extract or culture supernatants with $0.125 \mathrm{ml}$ of a $5 \mathrm{~g} \mathrm{l}^{-1}$ solution of PNPG in acetate buffer $\mathrm{pH} 5.3$ for $60 \mathrm{~min}$ at $37^{\circ} \mathrm{C}$. An aliquot $(2.25 \mathrm{ml})$ of a solution of $40 \mathrm{~g} \mathrm{l}^{-1} \mathrm{Na}_{2} \mathrm{CO}_{3}$ in distilled water was added to stop the reaction and samples were analysed on a spectrophotometer. Enzymic activity units were calculated as previously described (Cenamor et al., 1987). The assays were performed three times for each strain. 
Culture supernatants were obtained as previously described (Molina et al., 1987). Glucanse activity was measured in $0.05 \mathrm{ml}$ samples by addition of $2.5 \mu \mathrm{l}$ of a $1 \mathrm{mg} \mathrm{ml}^{-1}$ dilution of FDGP. Absorbance $(\lambda=510 \mathrm{~nm})$ was measured after incubation at $30^{\circ} \mathrm{C}$ for $3 \mathrm{~h}$ in darkness. The assays were performed three times with each strain.

Virulence assays. Male and female inbred Balb/c and DBA/2 mice (Charles River) weighing $18-22 \mathrm{~g}$ were used. Yeast strains were grown at $30^{\circ} \mathrm{C}$ on minimal medium agar plates (6.7 g Difco yeast nitrogen base $\mathrm{l}^{-1}, 20 \mathrm{~g}_{\text {glucose }} \mathrm{l}^{-1}, 20 \mathrm{~g}$ agar $\left.\mathrm{l}^{-1}\right)$. After $24 \mathrm{~h}$, cells were harvested, washed twice with PBS and diluted to the desired density in $0.5 \mathrm{ml}$ of the same buffer for injection into the lateral tail vein of the mice. Kidneys and brains from individual mice were removed aseptically and placed in a tissue homogenizer with $5 \mathrm{ml}$ or $3 \mathrm{ml} \mathrm{PBS}$, respectively. The number of viable yeast units in the specimens (six to eight mice per group) was determined by a plate dilution method on YED/chloramphenicol solid media. Results (means \pm standard deviation) are expressed as log c.f.u. per organ.

Antifungal susceptibility assays. The procedure of Anaissie et al. (1994) was used to determine MICs. Microtitre plates were inoculated with $1 \times 10^{4}$ cells $\mathrm{ml}^{-1}$ and incubated at $35^{\circ} \mathrm{C}$ for $48 \mathrm{~h}$. The antifungal assay was repeated three times only against those antifungal agents for which differences were observed in the corresponding initial MIC assay.

\section{RESULTS}

\section{XOG1 is not essential in C. albicans}

Disruption of the two alleles of the XOG1 gene was performed in a sequential manner following the strategy described elsewhere (Fonzi \& Irwin, 1993). As shown in Fig. 1, a 4.03 kb BglII-BamHI fragment from pCUB-6 carrying the URA3 gene flanked by the Salmonella his $G$ gene was inserted into the StyI site of the C. albicans XOG1 gene. Like ATCC strain 10261, CAI-4 was found to be heterozygous at the XOG1 locus (Chambers et al., 1993), thus allowing tracing of the chromosomal homologue in which gene replacement had taken place. Transformation with this linearized construction into strain CAI-4 yielded strains CNC30-a and CNC30-b (depending on which chromosome was affected). The estimated frequency of homologous integration at the XOG1 locus was $60 \%$. Excision of URA3 selected on 5 FOA plates yielded strains CNC31-a and CNC31-b, which were then used to select the $x$ og 1 null allele strains $\mathrm{CNC} 32-\mathrm{a}$ and $\mathrm{CNC} 32-\mathrm{b}$ and the corresponding CNC33$a$ and CNC33-b strains (Ura- background). For some of the subsequent functional studies, both the heterozygous and homozygous null allele strains $\mathrm{CNC} 31-\mathrm{a}$ and CNC31-b (relevant genotype $x o g 1 /$ XOG1) and CNC33$\mathrm{a}$ and CNC33-b (relevant genotype $x \circ 1 / \operatorname{xog} 1$ ) were used.

CNC30-a, CNC30-b, CNC32-a and CNC32-b showed no obvious growth differences as compared to wild-type strain SC5314 when growing exponentially at different temperatures $\left(30,37\right.$ and $\left.42^{\circ} \mathrm{C}\right)$ and in different synthetic minimal or rich media (data not shown). The final absorbances reached in stationary-phase cultures were also similar, indicating that deletion of the XOG1 gene does not induce obvious defects even in the stationary

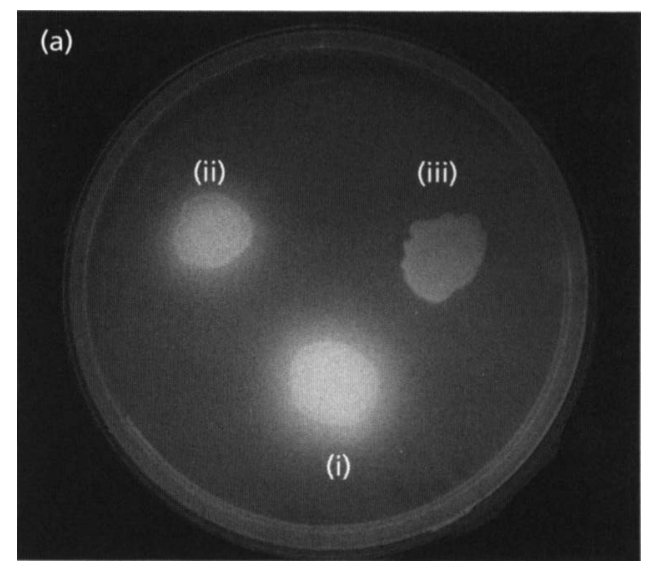

(b)

(i)

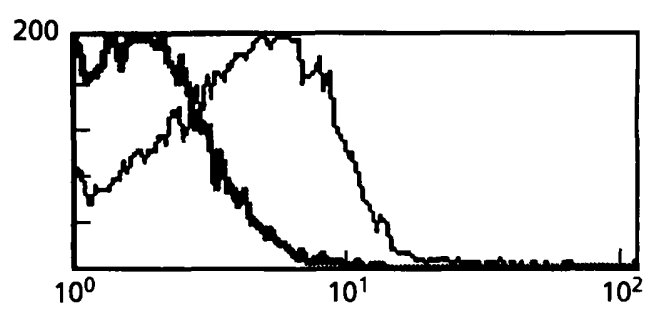

(ii)

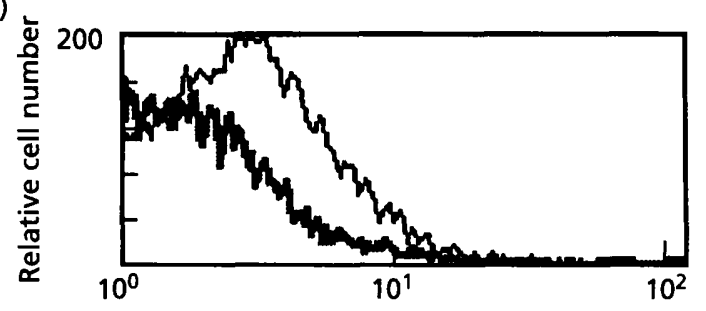

(iii)

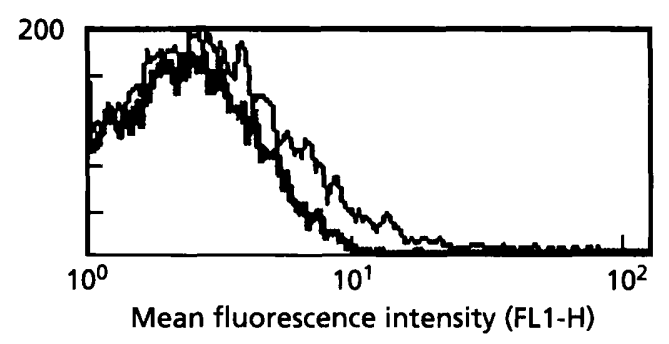

Fig. 2. Exoglucanase activity in intact cells of $C$. albicans strains SC5314 (wild-type, i); CNC30-a (xog1::hisG-URA3-hisG/XOG1, ii); and CNC32-a (xog1::hisG/xog1::hisG-URA3-hisG, iii). (a) Exoglucanase activity as observed by fluorescence of UVirradiated cells after MUG hydrolysis on solid medium. (b) Exoglucanase quantification by flow cytometry using the substrate FDGP. Controls (lacking substrate) are represented by the bold line. FL1-H was 14.85 for strain SC5314 (i), 8.3 for CNC30-a (ii) and 3.59 for CNC32-a (iii).

phase of growth. In addition, careful and exhaustive phase contrast microscopic observation of the three strains was performed, but no appreciable morpho- 

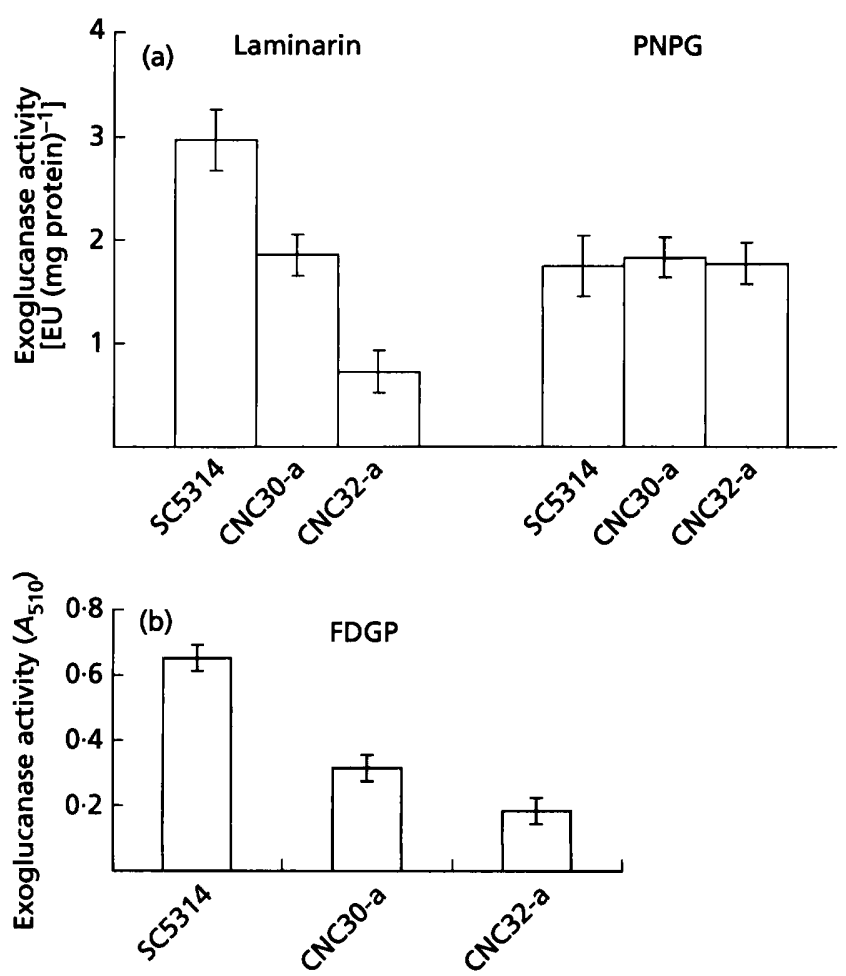

Fig. 3. Assay of exoglucanase activity in cell-free extracts (a) and supernatants (b) of C. albicans wild-type strain SC5314 and disrupted strains CNC30-a and CNC32-a. Activity in extracts was assayed using laminarin and PNPG as substrates, and in supernatants using FDGP as substrate. Bars represent standard deviations.

logical differences among them were observed, nor even when scanning and transmission electron microscopy were used (data not shown). Finally, neither the homozygous nor the heterozygous null strains showed appreciable differences with regard to the timing and morphological appearance of filaments when dimorphic transition was induced either in Lee's medium or serum ( $24 \mathrm{~h}$ at $37^{\circ} \mathrm{C}$, data not shown). Collectively, these data indicate that the XOG1 gene is not essential in $C$. albicans and is apparently not involved in dimorphic transition.

\section{XOG1 encodes the major exoglucanase activity in C. albicans}

Exoglucanase activity was measured in the wild-type strain SC5314, and in xog1::hisG-URA3-hisG/XOG1 and $x \circ 1::$ hisG/ $\operatorname{xog} 1::$ hisG-URA3-hisG strains on solid medium using MUG and in liquid medium using FDGP as substrates (Fig. 2). A significant reduction was observed in the fluorescence emitted by $\operatorname{xog} 1:$ : hisGURA3-hisG/XOG1 cells when irradiated under UV light compared to the wild-type control strain. This result was clearly confirmed using cell-free extracts and supernatants from exponentially growing liquid cultures (see Methods), using laminarin and FDGP as substrates (Fig. 3). Using PNPG as substrate, no significant differences were detected. Thus, deletion of XOG1 did not result in a reduction in PNPG activity, in agreement with previous reports (Molina et al., 1987; Luna Arias et al., 1991) and indicating that the major glucanase activity from $C$. albicans does not show significant activity against PNPG.

Interestingly, the single knock-out strains $\mathrm{CNC} 30$-a and $\mathrm{CNC} 30-\mathrm{b}$ displayed an intermediate phenotype, indicating that deletion of a single allele results in a decrease in the total glucanase activity of the cell. No differences were observed between $\mathrm{CNC} 30-\mathrm{a}$ and $\mathrm{CNC} 30-\mathrm{b}$, suggesting that this effect may be the result of a different gene dosage rather than functional differences between the XOG1 alleles.

\section{XOG1 null mutants are virulent}

To determine whether the glucanase XOG1 gene plays a role in pathogenicity, both the parental SC5314 strain and the $x \operatorname{og} 1::$ hisG/xog1::hisG-URA3-hisG strains were tested for virulence in systemic infections. Two inbred strains of mice were used: Balb/c mice (less susceptible to this kind of infection) develop $T_{H} 1$ associated immunity while DBA/ 2 animals (more susceptible) are characterized by a predominance of $\mathrm{T}_{\mathrm{H}} 2$ response (Hector et al., 1982; Romani et al., 1992, 1993). To evaluate the patterns of susceptibility of $\mathrm{Balb} / \mathrm{c}$ and DBA/2 mice to systemic infection by $C$. albicans SC5314 and the xog1 null mutant, the animals were injected in the lateral tail vein with four different doses of yeast cells : $1 \times 10^{7}, 1 \times 10^{6}, 1 \times 10^{5}$ and $5 \times 10^{4}$. The course of the infection was monitored by mortality parameters : median survival time (MST) and number of dead mice out of the total (D/T), as well as the level of fungal load in representative organs, i.e. kidney and brain. Table 2 shows that the inoculation of high doses $\left(1 \times 10^{7}\right.$ and $1 \times 10^{6}$ cells) of both strains of C. albicans killed all the mice in few days. Inoculation of lower doses led to the appearance of chronic infection in $\mathrm{Balb} / \mathrm{c}$ mice, whilst in DBA mice all the animals died, even with the lowest dose. A difference in MST was only observed in Balb/c mice inoculated with $1 \times 10^{6}$ cells, but without statistical significance $(P>0.05$, ANOVA test) when all the mice were considered. The degree of fungal load in the kidneys and brains of the infected mice was also measured (Table 2). As can be seen, both C. albicans strains behaved in a similar fashion: the log c.f.u. recovered from the kidneys was high (between 4 and 6) in both strains of mice, whilst renal clearance was observed in some of the Balb/c mice when the $1 \times 10^{5}$ and $5 \times 10^{4}$ doses were used. Statistical analysis (ANOVA test) was applied and the differences in renal load between both strains of $C$. albicans were found to be not significant $(P=0 \cdot 230)$. By contrast, the number of cells recovered from brain was significantly different between the parental and the mutant strains $(P<0.001)$. As mentioned above, DBA/ 2 mice were more susceptible, as reflected in a high log c.f.u., even at the lower doses whereas $\mathrm{Balb} / \mathrm{c}$ mice inoculated with these doses showed brain clearance. Taken together, these results indicate that $x \circ g 1$ null mutants are as virulent as the 
Table 2. Course of $C$. albicans infection in Balb/c and DBA/2 mice

Age-matched mice of either strain were challenged with various doses of C. albicans SC5314 or CNC32-a cells as described in Methods.

\begin{tabular}{|c|c|c|c|c|c|c|c|}
\hline \multirow{2}{*}{$\begin{array}{l}\text { Challenge } \\
\text { dose }\end{array}$} & \multirow{2}{*}{$\begin{array}{c}\text { C. albicans } \\
\text { strain }\end{array}$} & \multicolumn{3}{|c|}{ Balb/c mice } & \multicolumn{3}{|c|}{ DBA/2 mice } \\
\hline & & $\begin{array}{r}\text { MST } \\
(d)^{*}\end{array}$ & $\begin{array}{l}\log \text { C.f.u. per } \\
\text { kidney } \dagger\end{array}$ & $\begin{array}{l}\log \text { C.f.u. } \\
\text { per brain } \dagger\end{array}$ & $\begin{array}{r}\text { MST } \\
(d)^{*}\end{array}$ & $\begin{array}{c}\log \text { C.f.u. } \\
\text { per kidneyt }\end{array}$ & $\begin{array}{l}\log \text { C.f.u. } \\
\text { per brain } †\end{array}$ \\
\hline \multirow[t]{2}{*}{$10^{7}$} & SC5314 & 1 & $6.03 \pm 0.84$ & $4 \cdot 47 \pm 0 \cdot 13$ & 1 & NT & NT \\
\hline & CNC32-a & 1 & $5 \cdot 73 \pm 0 \cdot 13$ & $2 \cdot 19 \pm 0.51$ & 1 & NT & NT \\
\hline \multirow[t]{2}{*}{$10^{6}$} & SC5314 & 3 & $5.93 \pm 0.18$ & $4 \cdot 04 \pm 0 \cdot 22$ & 1 & $6 \cdot 02 \pm 0.92$ & $3 \cdot 81 \pm 0 \cdot 16$ \\
\hline & $\mathrm{CNC} 32-\mathrm{a}$ & 7 & $4.79 \pm 0.47$ & $2 \cdot 56 \pm 0.91$ & 1 & $5 \cdot 52 \pm 0 \cdot 17$ & $3.64 \pm 0.09$ \\
\hline \multirow[t]{2}{*}{$10^{5}$} & SC5314 & $>60$ & $4 \cdot 32 \pm 1 \cdot 51 \neq$ & $-\ddagger$ & 4 & $5 \cdot 17 \pm 0 \cdot 76$ & $3 \cdot 70 \pm 0 \cdot 19$ \\
\hline & CNC32-a & $>60$ & $4 \cdot 58 \pm 1 \cdot 12 \ddagger$ & $-\ddagger$ & 4 & $5 \cdot 78 \pm 0 \cdot 20$ & $3 \cdot 26 \pm 0.52$ \\
\hline \multirow[t]{2}{*}{$5 \times 10^{4}$} & SC5314 & $>60$ & $4 \cdot 87 \pm 0.96 \ddagger$ & $-\ddagger$ & 7 & $6.45 \pm 0.56$ & $4.53 \pm 0.50$ \\
\hline & CNC32-a & $>60$ & $4.35 \pm 1.49 \ddagger$ & $-\ddagger$ & 7 & $5.54 \pm 0.59$ & $2.99 \pm 0.66$ \\
\hline
\end{tabular}

NT, Not tested.

*MST, median survival time.

† Parallel groups of mice were killed the day before that indicated in the MST column for quantification of c.f.u. in their kidneys and brains. Values shown are means \pm SD of six to eight mice. Statistically significant differences were not found betweeen values for kidney $(P=0.230)$ but were found for brain $(P<0.001)$, as determined by ANOVA tests by $C$. albicans strain with mice and dose as covariates.

$\ddagger$ Some or all the mice showed infection clearance.

Table 3. Susceptibility of C. albicans strains SC5314 and CNC32-a to different antifungals

Values shown are means of three determinations $( \pm S D)$ where applicable

\begin{tabular}{|lcc|}
\hline Antifungal & \multicolumn{2}{c|}{ MIC $\left(\mu \mathrm{g} \mathrm{ml}^{-1}\right)$} \\
\cline { 2 - 3 } & SC5314 & CNC32-a \\
\hline Papulacandin B & $0 \cdot 52 \pm 0 \cdot 22$ & $0 \cdot 26 \pm 0 \cdot 11$ \\
Cilofungin & $0 \cdot 157 \pm 0 \cdot 068$ & $0 \cdot 08 \pm 0 \cdot 03$ \\
Nikkomycin & $0 \cdot 0087 \pm 0 \cdot 0057$ & $0 \cdot 072 \pm 0.048$ \\
Calcofluor & $33 \pm 14 \cdot 43$ & $41 \cdot 6 \pm 14 \cdot 43$ \\
5-fluorcytosine & $0.08 \pm 0.034$ & $0 \cdot 16 \pm 0.069$ \\
Amphotericin B & $0 \cdot 24$ & $0 \cdot 24$ \\
Miconazole & 0.48 & $0 \cdot 48$ \\
Trichodermine & 0.078 & $0 \cdot 078$ \\
Canavanine & 32 & 32 \\
Caffeine & 485.5 & 485.5 \\
2-Deoxyglucose & 200 & 200 \\
\hline
\end{tabular}

parental strain, in spite of having a reduced capacity to colonize the brain.

\section{Deletion of XOG1 and effects on the cell wall}

Although deletion of XOG1 did not involve major phenotypic changes, we further characterized the mutant cells as regards their susceptibility to a wide variety of antifungals to identify putative underlying differences.
We used a set of unrelated compounds that affect different processes in fungal physiology. No differences were observed for antibiotics that interfere with processes such as protein synthesis (trichodermin), ergosterol biosynthesis (miconazole), membrane functionality (amphotericin B) or that behave as toxic metabolites (2-deoxyglucose, canavanine) (Table 3). However, null mutant cells were more susceptible to antifungals that inhibit $1,3-\beta$-glucan biosynthesis, such as cilofungin and papulacandin B (only a slight variation in the sensitivity shown by the wild-type strain with respect to the mutant was observed). Since the differences were repeatable, even though they were very small, these results appear to be consistent with a slight difference in the cell wall between the wild-type and mutant strains. The antifungals act at the same level intefering with cell wall synthesis and/or assembly; therefore, although not very prominent, we believe that the aforementioned differences must have some functional meaning. In parallel, cells were found to be more resistant to nikkomycin, an antibiotic that inhibits chitin biosynthesis in C. albicans (Chapman et al., 1992). This suggests subtle differences in cell wall architecture. To visualize chitin septa, the fluorochromes calcofluor (Pringle, 1984) and primuline (Duffus et al., 1984) were used. Calcofluor and primuline are fluorochromes that show high affinity for yeast cell wall chitin and, in addition, calcofluor shows strong antifungal activity when used at high concentrations (Roncero \& Duran, 1985). This different susceptibility between the mutant and the wild-type cells may reflect differences in the cell wall composition. This could affect the permeability and hence the accessibility of the antifungal - and the 
(a)

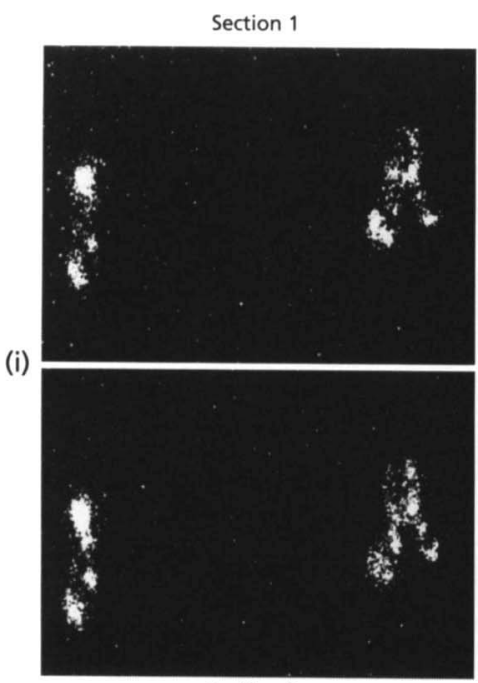

Section 3

Section 1

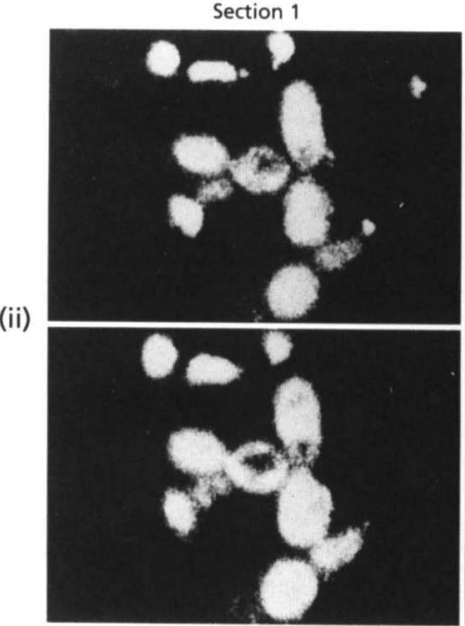

Section 3

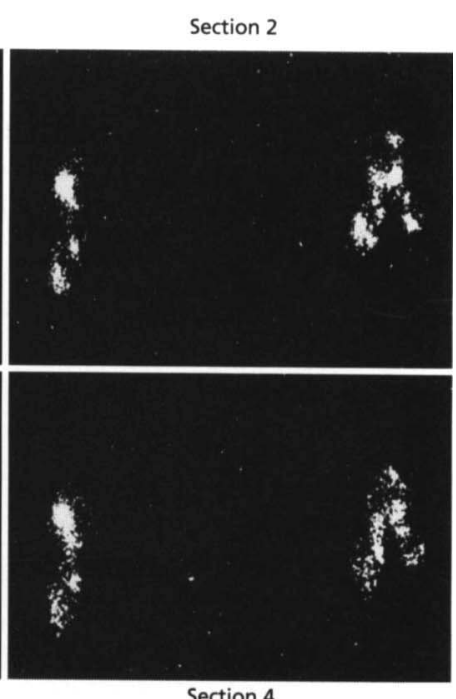

Section 4

Section 2

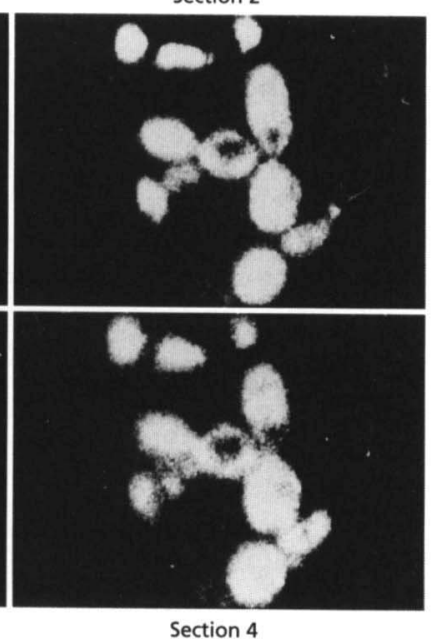

(b)
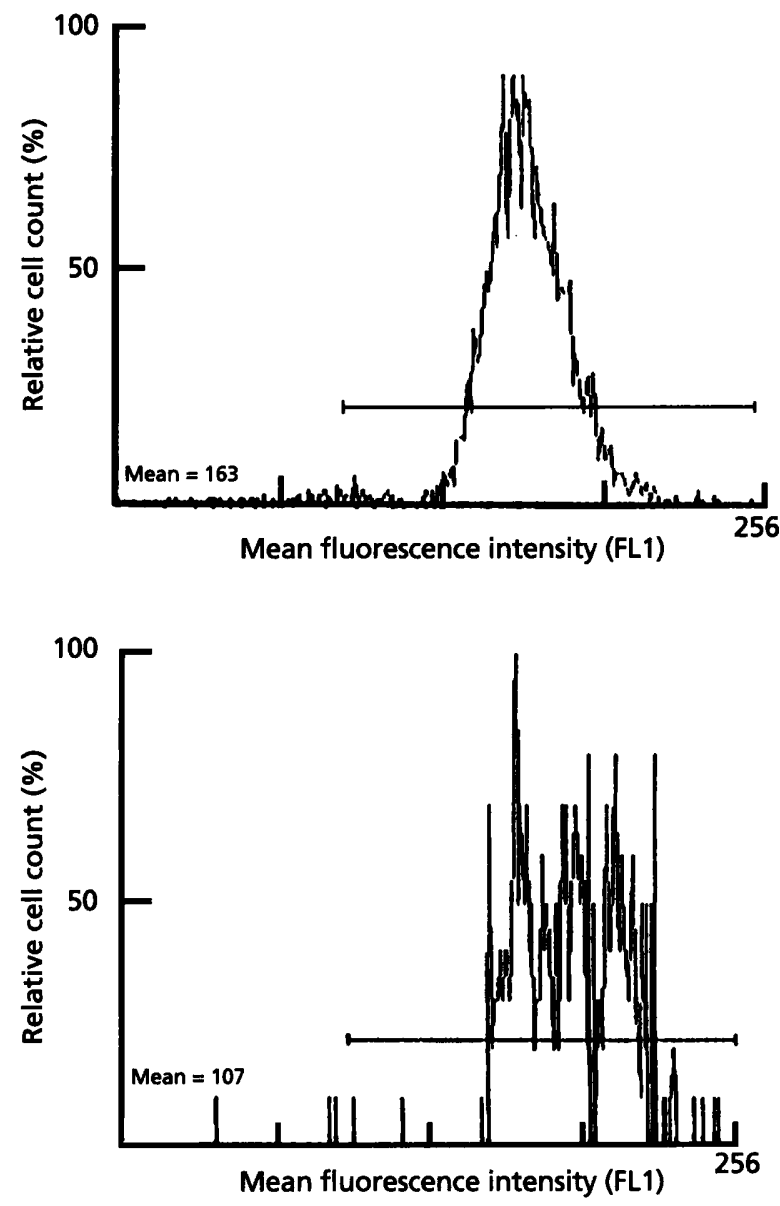

Fig. 4. Relative chitin content in C. albicans strains SC5314 (wild-type, i) and CNC32-a (xog1 null mutant, ii). (a) Distribution of chitin in progressive sagittal sections of infected mice separated by $0.5 \mu \mathrm{m}$ using confocal microscopy and primuline as fluorochrome. The signal detected corresponds to primuline binding to chitin-rich zones. In the wild-type strain (i) the chitin is associated with the bud scars, whereas in the mutant strain (ii) it is distributed randomly throughout the cell. (b) Chitin quantification by flow cytometry using calcofluor as fluorochrome. The value in the lower left corner represents the mean intensity of fluorescence (FL1).

different suceptibilities observed may therefore reflect a difference, perhaps subtle, at the level of cell wall composition or organization. Mutant cells emitted more fluorescence due to primuline excitation than wild-type strain cells (Fig. 4a). Similar results were obtained when the fluorescence emitted by calcofluor was analysed by flow cytometry (Fig. 4b).

\section{DISCUSSION}

The recent development of an efficient gene disruption system in C. albicans (Fonzi \& Irwin, 1993) has enabled an assessment of the role of individual genes in $C$. albicans physiology. In this work, we characterized a strain deficient in XOG1, a gene recently cloned using a reverse genetic approach (Chambers et al., 1993). Our results confirm previous studies from our laboratory and others (Chambers \& Sullivan, 1993, Luna Arias et al., 1991; Molina et al., 1987), pointing to the existence of a major glucanase activity in C. albicans, and identified XOG1 as responsible for this $1,3-\beta$-glucanase activity. However, they also suggest the existence of other glucanases, since $x \circ g 1$ null mutants cells still have residual glucanase activity. Removal of the major exoglucanase activity in the C. albicans $x \circ g 1$ null strain may allow, as in the case of $S$. cerevisiae, cloning of other minor glucanases (Correa, 1993; Muthukumar et al., 1993; San Segundo et al., 1993). 
A relevant and additional conclusion from our results is that the XOG1 gene is not essential in C. albicans. This observation is in accordance with the role of exoglucanases in S. cerevisiae, since none of the three exoglucanase genes cloned to date-EXG1 (Nebreda et al., 1986), EXG2 (Correa, 1993) and SSG1 (Muthukumar et al., 1993; San Segundo et al., 1993) - have been implicated in morphogenic processes. The existence of different genes with an apparently similar function points to an important (although hitherto cryptic) role of glucanases in cell physiology. However, it should be stressed that disruption of either of the XOG1 alleles elicits an intermediate decrease in exoglucanase activity of about $40 \%$. This suggests that the reduction in activity may be due to gene dosage and not allelic differences. Furthermore, disruption of both alleles elicits an $80 \%$ decrease in exoglucanase activity.

Since the timing and morphological appearance of mycelia were similar in the wild-type and single and double XOG1 disruptants, another important observation of this work is that the XOG1 gene is not involved in dimorphism. Furthermore, the XOG1 gene can be used as a reporter to identify the genes involved in dimorphic transition.

However, it is also evident that disruption of XOG1 leads to subtle but consistent changes in the cell wall, as deduced from the effect of its disruption in antifungal susceptibility and the fluorescence pattern with the cell wall fluorochromes primuline and calcofluor. Nevertheless, since the xog1 null mutants show enhanced susceptibility to $\beta$-glucan inhibitors and since this mutant also shows more resistance to nikkomycin, a chitin inhibitor, another interpretation could be that chitin and glucan might play compensatory roles in cell wall architecture, as has been suggested for $S$. cerevisiae (Kollár et al., 1995; Popolo et al., 1997). If the level of chitin synthesis in the mutant strain were higher than in the wild-type it would appear logical that higher doses of the antifungal nikkomycin would be required to inhibit growth. The data presented in Fig. 4 can be explained using two different lines of discussion: (1) elimination of the exoglucanase could have produced an overall change in cell wall permeability, allowing a more efficient staining with the dyes used; (2) the increase in fluorescence afforded by primuline and calcofluor could have been due to an increase in the amount of chitin in the cell wall of the mutant. However, it should be stressed that neither calcofluor nor primuline stains are specific for chitin in all contexts (Duffus et al., 1984; Pringle, 1984). Despite this, it has been observed that these fluorochromes show strong affinity for the chitin present in the cell wall of yeasts (Roncero \& Duran, 1985). Since we only used these fluorochromes for comparative purposes, we believe that it is not very relevant that that they are not exclusively specific for chitin. The aim of this work is merely to pinpoint some subtle differences between the mutant and wild-type strains, knowing that more detailed studies would be required to define such differences at a molecular level.

Due to the opportunistic pathogenic nature of $C$. albicans, we undertook a detailed analysis of the role of the XOG1 gene in virulence. A C. albicans mutant disrupted in a cell wall biosynthetic enzyme (chs2) showed no differences in dimorphism or in virulence (Gow et al., 1994). However, a recent report indicates that another chitin-deficient mutant (chs3) and a calcofluor-resistant mutant are less virulent (Bulawa et al., 1995). Despite this, Toshiyuki et al. (1996), analysing the virulence of chs 3 mutants found no differences in virulence as compared with the wild-type strain and attributed this to the strains and assay methods used. In this study we show that in an experimental murine model the $\operatorname{xog} 1$ null mutant is as pathogenic as the wildtype strain, as shown by similar median survival time (MST) and number of dead mice out of the total (D/T) values. Concerning the ability to colonize organs, statistically significant differences were only found in the $\log$ c.f.u. recovered from brain.

The non-essential nature of XOG1 gene rules out its use as an antifungal target. However, it could be a very attractive reporter gene. Although in C. albicans there are some recently developed systems (Leuker et al., 1992; Myers et al., 1995; Srikantha et al., 1996, Cormack et al., 1997), none of them displays the versatility of the exoglucanase system for its use in flow cytometry, biochemical measures and agar plate detection in gene reporter assays. Another important point is that since deletion of the XOG1 gene does not affect virulence, it would be possible to set up a strategy aimed at the isolation and identification of C. albicans genes involved in virulence using the exoglucanase as a reporter. A similar conceptual approach has been described by Mahan et al. (1993a, b) for the selection of bacterial virulence genes.

\section{ACKNOWLEDGEMENTS}

We thank Dr F. del Rey for helpful discussions and Dr P. Sullivan for sending us the XOG1 gene. This work was supported by a grant from the Fondo de Investigaciones Sanitarias de la Seguridad Social (no. 95/0073-01).

\section{REFERENCES}

Anaissie, E. J., Karyotakis, N. C., Hachem, R., Dignani, M. C., Rex, J. H. \& Paetznick, V. (1994). Correlation between in vitro and in vivo activity of antifungal agents against Candida species. J Infect Dis 170, 384-389.

Ashwell, G. (1957). Colorimentric analysis of sugars. Methods Enzymol 3, 73-105.

Boeke, J. D., Trueheart, J., Natsoulis, G. \& Fink, G. R. (1987). 5Fluoroorotic acid as a selective agent in yeast molecular genetics. Methods Enzymol 154, 164-175.

Bradford, M. M. (1976). A rapid and sensitive method for the quantitation of microgram quantities of protein utilizing the principle of protein-dye binding. Anal Biochem 72, 248-254.

Bulawa, C. E., Miller, D. W., Henry, L. K. \& Becker, J. M. (1995). Attenuated virulence of chitin-deficient mutants of Candida albicans. Proc Natl Acad Sci USA 92, 10570-10574.

Cannon, R. D., Jenkinson, H. F. \& Shepherd, M. G. (1990). Isolation and nucleotide sequence of an autonomously replicating 
sequence (ARS) element functional in Candida albicans and Saccharomyces cerevisiae. Mol Gen Genet 221, 210-218.

Cannon, R. D., Jenkinson, H. F. \& Shepherd, M. G. (1992). Cloning and expression of Candida albicans ADE2 and proteinase genes on a replicative plasmid in Candida albicans and in Saccharomyces cerevisiae. Mol Gen Genet 235, 453-457.

Cenamor, R., Molina, M., Galdona, J., Sánchez, M. \& Nombela, C. (1987). Production and secretion of Saccharomyces cerevisiae $\beta$ glucanases: differences between protoplast and periplasmic enzymes. J Gen Microbiol 133, 619-628.

Chambers, R. S. \& Sullivan, P. A. (1993). Expression of the exoglucanase gene in yeast and hyphal forms of Candida albicans. FEMS Microbiol Lett 111, 63-68.

Chambers, R. S., Broughton, M. J., Cannon, R. D., Carne, A., Emerson, G. W. \& Sullivan, P. A. (1993). An exo- $\beta$-(1,3)-glucanase of Candida albicans: purification of the enzyme and molecular cloning of the gene. J Gen Microbiol 139, 325-334.

Chapman, T., Kinsman, O. \& Houston, J. (1992). Chitin biosynthesis in Candida albicans grown in vitro and in vivo and its inhibition by nikkomycin Z. Antimicrob Agents Chemother 36, 1909-1914.

Cid, V. J., Álvarez, A. M., Santos, A. I., Nombela, C. \& Sánchez, M. (1994). Yeast exo- $\beta$-glucanases can be used as efficient and readily detectable reporter genes in Saccharomyces cerevisiae. Yeast 10, $747-756$.

Cid, V. J., Duran, A., Delrey, F., Snyder, M. P., Nombela, C. \& Sánchez, M. (1995). Molecular basis of cell integrity and morphogenesis in Saccharomyces cerevisiae. Microbiol Rev 59, 345-386.

Cormack, B. P., Bertram, G., Egerton, M., Gow, N. A. R., Falkow, S. \& Brown, A. J. P. (1997). Yeast-enhanced green fluorescent protein (yEGFP): a reporter of gene expression in Candida albicans. Microbiology 143, 303-311.

Correa, J. (1993). Caracterización del gen EXG2 de Saccharomyces cerevisiae. PhD thesis, University of Salamanca, Spain.

Duffus, J. H., McDowell, W. \& Manners, D. J. (1984). The use of primuline to identify the septum polysaccharide of the fission yeast Schizosaccharomyces pombe. Stain Technol 59, 79-82.

Fleet, G. H. \& Manners, D. J. (1976). Isolation and composition of an alkali-soluble glucan from the cell walls of Saccharomyces cerevisiae. J Gen Microbiol 94, 180-192.

Fonzi, W. A. \& Irwin, M. Y. (1993). Isogenic strain construction and gene mapping in Candida albicans. Genetics 134, 717-728.

Fox, J. L. (1993). Fungal infection rates are increasing. ASM News $10,515-518$

de la Fuente, J. M., Álvarez, A., Nombela, C. \& Sánchez, M. (1992). Flow cytometric analysis of Saccharomyces cerevisiae autolytic mutants and protoplasts. Yeast 8, 39-45.

Gillum, A. M., Tsay, E. Y. H. \& Kirsch, D. R. (1984). Isolation of the Candida albicans gene for orotidine- $5^{\prime}$-phosphate decarboxylase by complementation of $S$. cerevisiae ura3 and E. coli pyrF mutations. Mol Gen Genet 198, 179-182.

Gow, N. A. R., Robbins, P. W., Lester, J. W., Brown, A. J. P., Fonzi, W. A., Chapman, T. \& Kinsman, O. S. (1994). A hyphal-specific chitin synthase gene (CHS2) is not essential for growth, dimorphism, or virulence of Candida albicans. Proc Natl Acad Sci USA 13, 6216-6220.

Hanahan, D. (1988). Techniques for transformation of E. coli. In DNA Cloning, pp. 109-135. Edited by D. M. Glover. Oxford: IRL Press.

Hector, R. F., Domer, J. E. \& Carrow, E. W. (1982). Immune responses to Candida albicans in genetically distinct mice. Infect Immun 38, 1020-1028.

Herreros, E., Garcla-Sáez, M. I., Nombela, C. \& Sánchez, M. (1992). A reorganized Candida albicans DNA sequence promoting homologous non-integrative genetic transformation. Mol Microbiol 6, 3567-3574.

Kollár, R., Petráková, E., Ashwell, G., Robbins, P. W. \& Cabib, E. (1995). Architecture of the yeast cell wall: the linkage between chitin and $\beta-(1,3)$-glucan. $J$ Biol Chem 3, 1170-1178.

Kuranda, M. J. \& Robbins, P. W. (1987). Cloning and heterologous expression of glycosidase genes from Saccharomyces cerevisiae. Proc Natl Acad Sci USA 84, 2585-2589.

Kurtz, M. B., Kelly, R. \& Kirsch, D. R. (1990). Molecular genetics of Candida albicans. In The Genetics of Candida, pp. 21-74. Edited by D. R. Kirsch, R. Kelly \& M. B. Kurtz. Boca Raton, FL: CRC Press.

Lee, K. L., Buckley, H. R. \& Campbell, C. C. (1975). An amino acid liquid synthetic medium for the development of mycelial and yeast forms of Candida albicans. J Med Vet Mycol 13, 148-153.

Leuker, C. E., Hahn, A. M. \& Ernst, J. F. (1992). $\beta$-Galactosidase of Kluyveromyces lactis (Lac4p) as reporter of gene expression in Candida albicans and C. tropicalis. Mol Gen Genet 235, 235-241.

Luna Arias, J. P., Andaluz, E., Ridruejo, J. C., Olivero, I. \& Larriba, G. (1991). The major exoglucanase from Candida albicans: a nonglycosylated secretory monomer related to its counterpart from Saccharomyces cerevisiae. Yeast 7, 833-841.

Mahan, M. J., Slauch, J. M., Hanna, P. C., Camilli, A., Tobias, J. W., Waldor, M. K. \& Mekalanos, J. J. (1993a). Selection for bacterial genes that are specifically induced in host tissues: the hunt for virulence factors. Infect Agents Dis 2, 263-268.

Mahan, M. J., Slauch, J. M. \& Mekalanos, J. J. (1993b). Selection of bacterial virulence genes that are specifically induced in host tissues. Science 259, 686-688.

Molina, M., Cenamor, R. \& Nombela, C. (1987). Exo-1,3- $\beta$ glucanase activity in Candida albicans: effect of the yeast-tomycelium transition. J Gen Microbiol 133, 609-617.

Muthukumar, G., Suhng, S. H., Magee, P. T., Jewell, R. D. \& Primerano, D. A. (1993). The Saccharomyces cerevisiae SPR1 gene encodes a sporulation-specific exo- $\beta-(1,3)$-glucanase which contributes to ascospore thermotolerance. J Bacteriol 175, 386-394.

Myers, K. K., Sypherd, P. S. \& Fonzi, W. A. (1995). Use of URA3 as a reporter of gene expression in C. albicans. Curr Genet 27, 243-248.

Nebreda, A. R., Villa, T. G., Villanueva, J. R. \& del Rey, F. (1986). Cloning of genes related to exo- $\beta$-glucanase production by Saccharomyces cerevisiae: Characterization of an exo- $\beta$-glucanase structural gene. Gene 47, 245-259.

Nebreda, A. R., Vazquez de Aldana, C. R., Villa, T. G., Villanueva, J. R. \& del Rey, F. (1987). Heterogeneous glycosylation of the $E X G 1$ gene accounts for the two extracellular exo- $\beta$-glucanases of Saccharomyces cerevisiae. FEBS Lett 220, 27-30.

Nombela, C., Molina, M., Cenamor, R. \& Sánchez, M. (1988). Yeast $\beta$-glucanases: a complex system of secreted enzymes. Microbiol Sci 5, 328-332.

Pla, J., Pérez-Dlaz, R. M., Navarro-Garća, F., Sánchez, M. \& Nombela, C. (1995). Cloning of Candida albicans HIS1 gene by direct homologous complementation of a histidine auxotroph using an improved double-ARS shuttle vector. Gene 165, 115-120.

Pringle, J. R. (1984). Staining of bud scars and other cell wall chitin with calcofluor. Methods Enzymol 194, 734-735.

Popolo, L., Gilardelli, D., Bonfante, P. \& Vai, M. (1997). Increase in 
chitin as an essential response to defects in assembly of cell wall polymers in the ggp1 $1 \Delta$ mutant of Saccharomyces cerevisiae. J Bacteriol 179, 463-469.

del Rey, F., Vázquez de Aldana, C. R., Correa, J. \& San Segundo, P. (1994). Characterization of genes related to beta-glucanase production in $S$. cerevisiae. In 15 th International Conference on Yeast Genetics and Molecular Biology, Abstract 11-20A. Yeast 6 (Special Issue), 504.

Romani, L., Cenci, E., Mencacci, A., Spaccapelo, R., Grohmann, U., Puccetti, P. \& Bistoni, F. (1992). Gamma interferon modifies CD4 + subset expression in murine candidiasis. Infect Immun 60, $4950-4952$.

Romani, L., Mencacci, A., Cenci, E., Spaccapelo, R., Mosci, P., Puccetti, P. \& Bistoni, F. (1993). CD4+ subset expression in murine candidiasis. Th responses correlate directly with genetically determined susceptibility or vaccine-induced resistance. $J$ Immunol 150, 925-931.

Roncero, C. \& Duran, A. (1985). Effect of Calcofluor White and Congo Red on fungal cell wall morphogenesis: in vivo activation of chitin polymerization. $J$ Bacteriol $163,1180-1185$.

Sambrook, J., Fritsch, E. F. \& Maniatis, T. (1989). Molecular Cloning: a Laboratory Manual, 2nd edn. Cold Spring Harbor, NY: Cold Spring Harbor Laboratory.

San Segundo, P., Correa, J., Vázquez de Aldana, C. R. \& del Rey, F. (1993). SSG1, a gene encoding a sporulation-specific $\beta$ - $(1,3)$ glucanase in Saccharomyces cerevisiae. J Bacteriol 175, 38233837.
Santos, T., Nombela, C., Villanueva, J. R. \& Larriba, G. (1979a). Characterization and synthesis regulation of Penicillium italicum $\beta$-(1,6)-glucanase. Arch Microbiol 121, 265-270.

Santos, T., del Rey, F., Conde, J., Conde, J. R. \& Nombela, C. (1979b). Saccharomyces cerevisiae mutant defective in exo- $\beta$ (1,3)-glucanase production. J Bacteriol 139, 333-338.

Santos, T., del Rey, F., Villanueva, J. R. \& Nombela, C. (1982). A mutation (exb1-1) that abolishes exo- $\beta-(1,3)$-glucanase production does not affect cell wall dynamics in Saccharomyces cerevisiae. FEMS Microbiol Lett 13, 259-263.

Somogyi, M. (1952). Notes on sugar determination. J Biol Chem 195, 19-23.

Srikantha, T., Klapach, A., Lorenz, W. W., Tsai, L. K., Laughlin, L. A., Gorman, J. A. \& Soll, D. R. (1996). The sea pansy Renilla reniformis luciferase serves as a sensitive bioluminescent reporter for differential gene expression in Candida albicans. J Bacteriol 178, 121-129.

Toshiyuki, M., Yabe, T., Sudoh, M., Yasuko, S., Nakajima, T., Arisawa, M. \& Yamada-Okabe, H. (1996). Role of three chitin synthase genes in the growth of Candida albicans. J Bacteriol 178, 2416-2419.

Vázquez de Aldana, C. R., Correa, J., San Segundo, P., Bueno, A., Nebreda, A. R., Mendez, E. \& del Rey, F. (1991). Nucleotide sequence of the exo- $\beta-(1,3)$-glucanase encoding gene, EXG1, of the yeast Saccharomyces cerevisiae. Gene 97, 173-182.

Received 11 March 1997; revised 27 May 1997; accepted 2 June 1997. 